\title{
Enhancing Regional Disaster Resilient Trade and Investment - Business Continuity Management
}

\author{
Yanling Lee ${ }^{1}$, Kenji Watanabe ${ }^{2}$ and Wei-Sen $\mathrm{Li}^{1}$ \\ ${ }^{1}$ APEC Emergency Preparedness Capacity Building Center \& National Science and \\ Technolo-gy Center for Disaster Reduction, Taipei, Taiwan \\ ${ }^{2}$ Nagoya Institute of Technology, Nagoya, Japan \\ sophiancdr@gmail.com
}

\begin{abstract}
The abstract should summarize the contents of the paper in short terms, i.e. 150-250 words. Large Corporates or global brands benefit from economic globalization and continues to grow in terms of comparative advantages across borders with synergy from integrated supply chain. When the large-scale disasters and catastrophes strike the Asia-Pacific Economic Cooperation (APEC) region - such as the 2004 Indian Ocean Tsunami or 2011 Great East Japan Earthquakes and tsunamis, the impact on global value chain highlight the needs to promote business continuity planning / management (BCP/BCM). Disasters bring along the threats with opportunities in the market place. For mitigating the impact, most of the world leading corporates urge to allocate resources to further strengthen the disaster resilient capability and secure business environment. In APEC, each economy is unique in its geopolitical conditions, but common in its goal to be $\mathrm{BCP} / \mathrm{BCM}$ capable. With missionary vision on promoting $\mathrm{BCP} / \mathrm{BCM}$. APEC deployed strategies at the various stages of preparatory work to managing risk and impact of large-scale natural disasters. APEC, as a pioneer, seeks to achieve the goal of sustainable quality growth and serve as learning points for interested economies who are in the midst of their BCP/BCM implementation. With review of the global and regional lessons learn from the large-scale disasters, this paper shared the regional efforts on disaster resilience, describe the strategic approaches and operational concept for emergency preparedness through technology and collaboration for enhancing global supply chain resilience across border.
\end{abstract}

Keywords: Business Continuity Planning / Management (BCP/BCM), Resilience, Collaborations, Asia-Pacific Economic Cooperation (APEC)

\section{Disaster Governance Strategic Approaches - Scaling up Disaster Resilience Capability Through Technology and Collaboration}

Globalization shows its vulnerability and complexity in business and manufacturing process as well as escalate the level of logistics support. Recall the economic impact of 
2004 The South-East Asia earthquake and tsunami, 2011 the Great East Japan Earthquakes and tsunamis coupled with the INES level 7 Fukushima nuclear power plants accident and 2016 Kaohsiung earthquakes in Taiwan; these earth-quakes caused the significant economic losses and challenged the continuity of business operations across the continents.

The market place may highly sensitive to natural disaster such as extreme events or large-scale earthquakes or floodings in terms of global value chains (GVCs) or sup-ply chain interruption. Failure to respond can lead to mass closures and bankruptcies. Followed the 2011 Great East Japan Earthquake and Tsunami and Thailand floods in 2011, the industries struggle for managing suppliers of information and communication technology (ICT) products ranging from hard-drives to component parts used in cars, cameras, electronics devices and etc. due to the supply chain interruption across border.

\subsection{Public Private Partnership (PPP) Engagement on Regional Business Continuity Planning / Management (BCP/BCM) Through Technology and Collaborations}

Disaster Risk Reduction (DRR) is key toward national security, economic quality growth, environmental sustainability and people's livelihoods. For regional consideration, a large-scale disaster could impact the GVCs/supply chain and hamper the regional economic growth and corporate profitability and even cease to exist. Hence, engaging regional join efforts on DRR becomes a global trend. After the 2011 Great Japan Earthquakes and Tsunami, the Asia-Pacific Economic Cooperation (APEC) initiate an multi-year project (1) to promote business resilience and implementing BCP with capacity building training workshop to help the small and medium size enterprises (SMEs), the multinational or international corporations to minimize supply chain interruption and enhance resilient manufacturing, trade and investments in APEC region.

The APEC successful stories shared as best practice in promoting BCP and PPP drawn the attention of global community. The Sendai Framework for Disaster Risk Reduction (SFDRR) (2) enforced during the Third UN World Conference on Disaster Risk Reduction (UN 3WCDRR) in 2015 promoted the value of resilience as well as encourage the PPP engagement and collaborations. SFDRR also encourages to adopt innovation, science and technology on DRR approaches such as big data and open data to facilitate the value-added information sharing on enhancing capacity building for multisectoral disaster resilience over higher public risk awareness and level of preparedness. In 2017, the 5th Global Platform for Disaster Risk Reduction in Cancun, Mexico further highlight the importance of DRR agenda with four priorities to declare the momentum 'From Commitment to Action" and special focuses on 'International Cooperation Initiatives' to promote international collaboration, public private partnership (PPP), critical infrastructure resilience with stakeholders' participation to achieve the goals of improving preparedness and national coordination for disaster response supported by strengthened modalities of international cooperation (3). 


\subsection{Options for Tackle the Risks}

The ability of a supply chain in coping with disasters are vary. It depends on the corporate risk tolerance (a limitation), preference (a choice) or appetites (a policy) for formulating appropriate strategy on DRR. (Fig. 1)

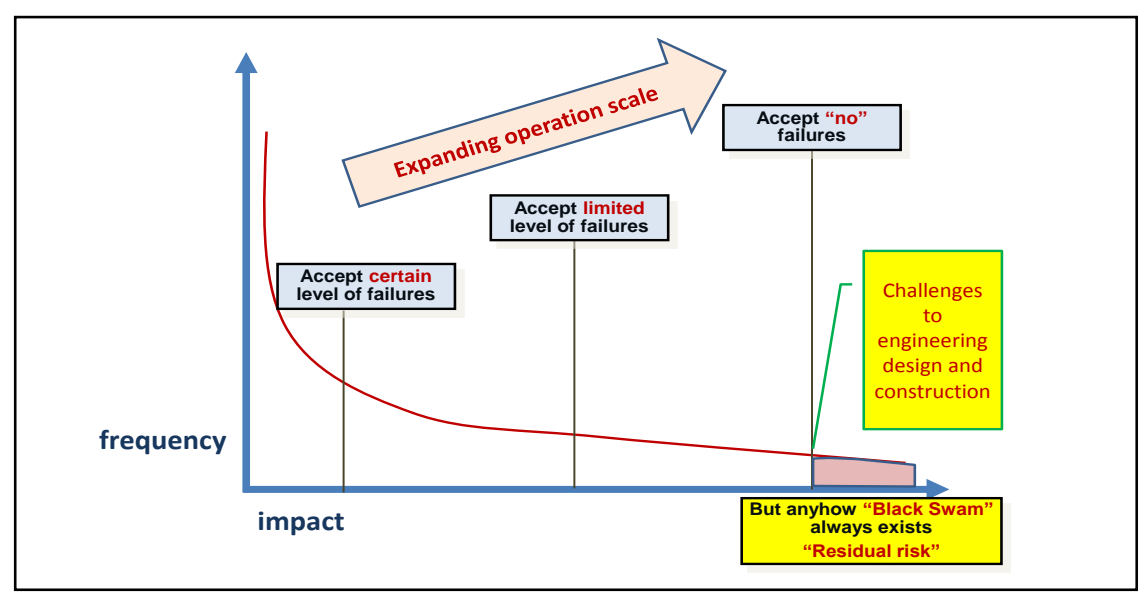

Fig. 1. Characteristics of risks for different scale of business - allowance of failure and interruption

When tackle the risks, supply chain, disaster managers have difficult options on whether: 1) to lean an operation and secure cost efficiency; 2) to build redundancy and secure supply and keep the shipping and delivery on time; 3 ) to maintain re-maining or residual capacity for operation and manage the shipment while supply chain interrupted if too big to build redundancy for the capital intensive invest-ment. Each approach has its pros and cons and applicable case by case. Hence, it is important to scaling up disaster resilient capability through state-of-the art tech-nology and PPP collaboration on information sharing, resources allocations and risks communication across border via clear common picture of situation for oper-ation. It is made possible if we can recruit local knowledge, join scenario based excises and drills based on the synergy of PPP in managing risks to mitigate the impact. With review of the global and regional lessons learn from the large-scale disasters, it is critical to formulate a strategic join operational framework for emer-gency preparedness via technology and collaborations on regional $\mathrm{BCP} / \mathrm{BCM}$ to enhance GVCs and supply chain resilience.

Looking at disaster-resilient business through the GVCs and supply chain - transboundary and end-to-end issues illustrated (Fig. 2), the risks can be divided into:

\section{External - managing by the public sector}

External (outside of the business complex or free trade zone):1) ensure the lifeline systems and utilities such as power, water, gas, telecommunications and transpor-tation are available; 2) identify the targeted types of natural hazards and impacts (direct and indirect) such as earthquakes, typhoons, landslides and droughts; 3) facilitate supply 
chain resilience such as coordinate end-to-end connectivity from up-stream supplies to customers with common standards to follow such as ISO 22301 ; 4) encourage information sharing and exchange in different phases of plan-ning, emergency response and recovery support by a systematic mechanism as an interface; 5) build up an inclusive platform to encourage dialogue

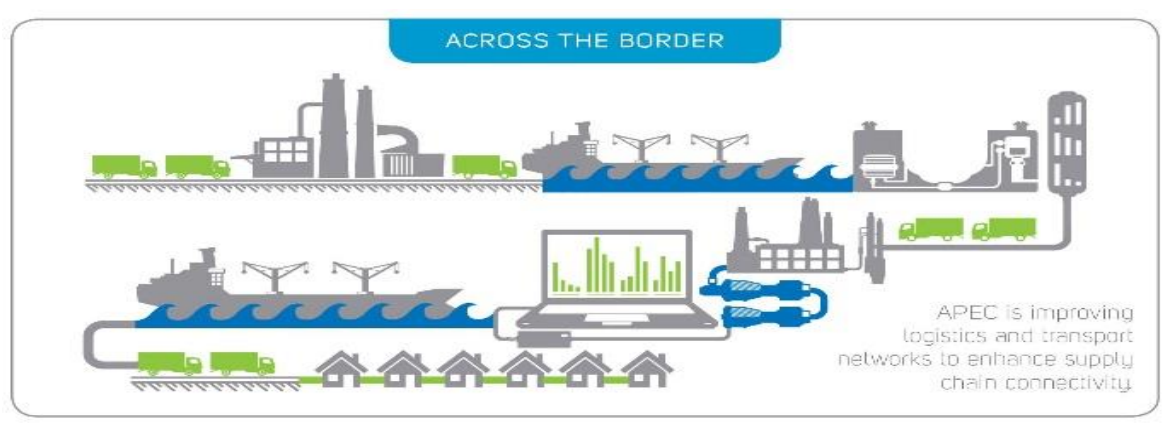

Fig. 2. Supply Chain Across the Border (4)

\section{Internal - managing by the private sector}

Internal (inside of the business complex or free trade zone):1) Connecting with business continuity plan for contingency, constantly monitoring risks and update key players to take same step and having join exercise; 2) Hosting scenario-based table-top exercise and drill according to the realistic situations and demands for better understanding on coping capability and capacity in extreme situations; 3) Facilitate internal information flow and decision making process by establish " $\mathrm{N}$ " to " 1 " and " 1 " to "Many", identify key information helping key decision makers, ensure the responsible authority of executing BCP for sharing information with key stakeholders outside.

\subsection{Taiwan Economy at Risk}

Taiwan's ICT industry has played an important role in the global market. Taiwan established science parks (Fig. 3) since 1980 for enhancing industry competitive-ness, technology transfer to attract foreign direct investments and state-of the art technology to boost the economy growth.

Targeting to build the science parks in Taiwan as one of the research and development hub in the Asia-Pacific, we clustering the upstream and downstream indus-tries within the science park. Looking at the strategy and structure of the industry in Taiwan, it is similar to most of the APEC member economies. SMEs contribute more than $70 \%$ of industrial output in Taiwan. (Fig. 4) These SMEs usually produce products on an original equipment manufacturer (OEM) or original design manu-facturer (ODM) basis (6).

The Science Park contribute $2.94 \%$ of economic growth and shoulder billions of trade and investment in Taiwan. ICT industry clustering in the science parks are the en-gine of Taiwan economic growth. In 2016, ICTs shoulder real rate of $3.2 \%$ GDP 
growth (7). Major investments include the expansion of Taiwan Semiconductor Manufacturing. The total revenue exceeds US $\$ 89.5$ billion in 2016, up 2.94 percent year on year to a record high. ICTs industry contributes to total of $14 \%$ of GDP (8) (Fig. 5)

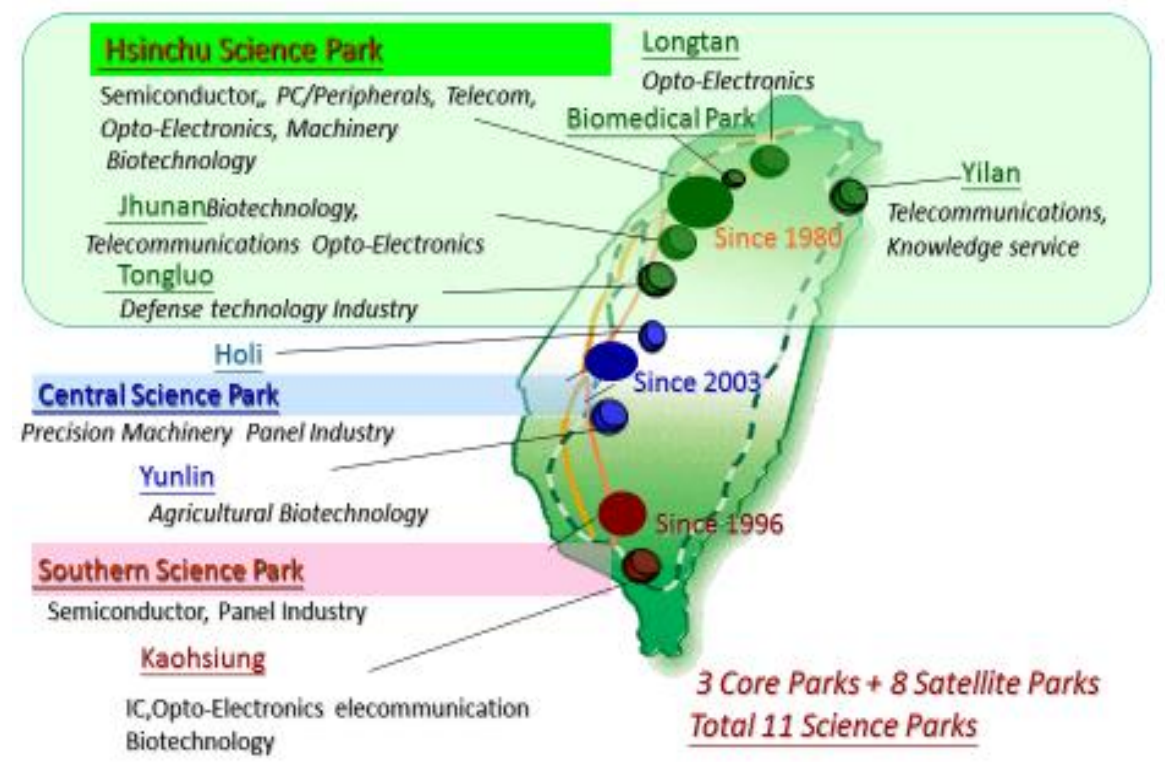

Fig. 3. Taiwan Science Park (5)

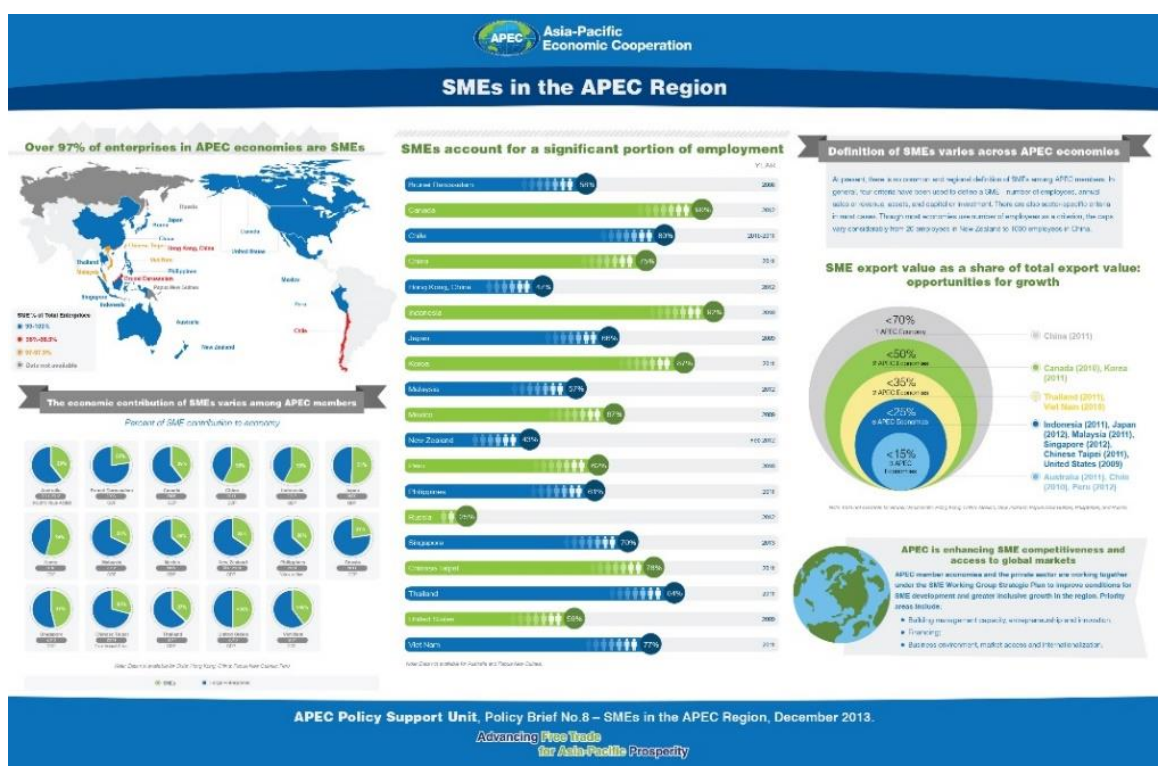

Fig. 4. SME in the APEC Region 


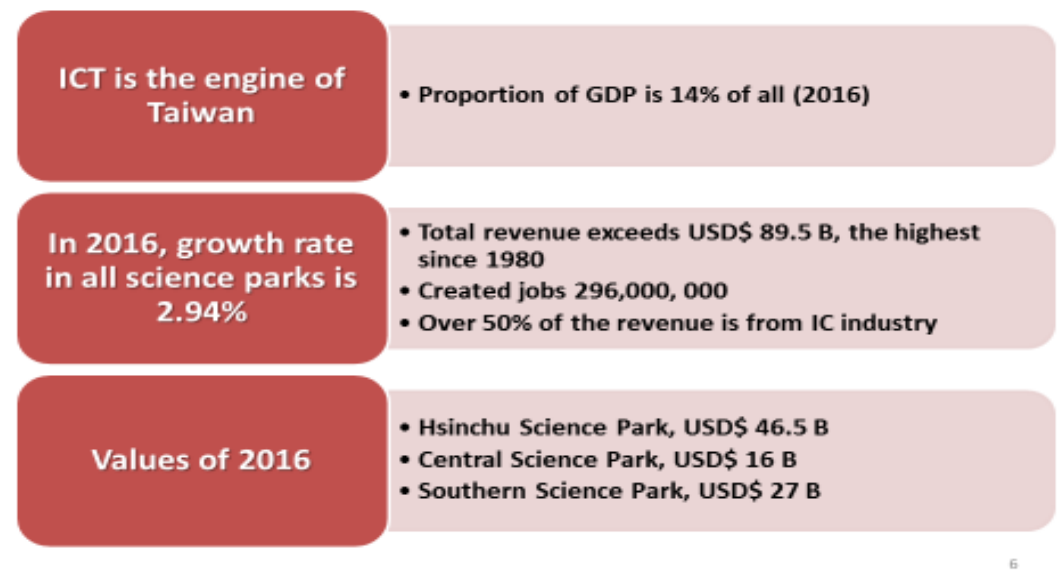

Fig. 5. Economic Contribution by Science Park in Taiwan

To sustain the economic growth, Taiwan government helps to bridge the information gap for emergency respond in the science parks and enhance the data process of the central emergency operation center (CEOC) operation while emergency. To interface with science park emergency operation, National Science and Technology Center for Disaster Reduction (NCDR) collaborated with Hsinchu Science Park Bureau to promote $\mathrm{BCP} / \mathrm{BCM}$ from the viewpoint of public and private partnership collabora-tions.

\subsection{TSMC Risk Management vs. Disasters in Taiwan}

Under the concept of business clustering, Taiwan Semiconductor Manufacturing Company (TSMC) and United Microelectronics Corporation (UMC), the world's largest and second largest semi-conductor manufacturers were established in the science parks to synergy the integration of industrial resources and product management connect with major international suppliers. TSMC coach the future BCP implementation from the experience of 1999 Chi-Chi Earthquakes (9) to minimize the impact on supply chain to uphold the ICT industry worldwide.

\section{Response Dilemma}

While disaster, it will escalate the intensity of a competitive market place. The strategy process among Micro Small and Medium Size Enterprises (MSMEs), SMEs, the large and global brands become more emergent than intended (10) The threat comes from substitutes and bargaining power of buyers will higher the industry rivalry in the business environment to certain extent (11) The emerging business continuity planning and management with supply chain resilience initiative can help stabilizing industries but cease to exist if disasters. BCP is a powerful ap-proach to identify the strategy's potential profitability if mitigating impact from disasters.

However, business sectors are having doubts and concerns to further respond or involve in the public private partnership engagement and tend to be hesitated to be transparent. The information disclosure to the market and their competitors may threat the 
corporates existence if credit ranking downgrade for loss. The corporate financing may become difficult than before. Moreover, the financial markets tend to be highly sensitive and vulnerable if panic in the marketplace while disaster strike. The hostile takeover, merge and acquisition will be active and easier through the financial markets while corporates in disasters if the stock prices goes down sharp-ly.

On the other hand, emergency preparedness need transparency on just-in-time decent appropriate information disclosure to some extent to succeed the team effort while disasters preparedness, response and recovery.

TSMC delivered a successful story after the 1999 Chi-Chi Earthquakes. Right after the quake, TSMC informed clients and set up hot-lines for Q\&A. Within first two days, 2 public announcements and 12 new releases. 5 days after, 100 interviews in 4 languages. A guarantee, "No delay to shipments". TMSC received more news coverages, $57 \%$, and $86 \%$ of them offered neutral or positive comments. TSMC's emergency response to their staff and clients is to send out the clear message at official level to protect their business and keep the shipment on time over imple-ment disaster preemptive mechanisms at corporate level. A business owners chal-lenges on the worst case and unexpected one to identify coping capacities and capa-bility are key to survive the disaster. Thus, quick and decent responses, just-in-time information disclosure and team efforts are the key to succeed the corporate crisis management in this case. This case share the value and importance of risk commu-nication and proper information disclosure in time of disaster.

For long-term sustainability, TSMC established its Enterprise Risk Management (ERM) program based on both its corporate vision and its long-term sustainability and responsibility to both industry and society. Meanwhile, TSMC BCM is imple-mented to managing the safety of production lines, services and shipment if disas-ters. In the case of TSMC, the capital intensive industry, cannot afford to have re-dundancy and have to go for no failures approaches. Base on the targeted goal and risk strategic approaches, a proper BCP can be realistic for implementation to achieve corporate disaster resiliency. Following the standards for the whole supply chain - ISO 22301, area BCM, TSMC exercised scenarios simulation to make plans and conduct drills for the worst or realistic worst case to test disaster resilient capacity and capability.

\subsection{Kaohsiung Earthquake on February 6th, 2016}

Taiwan, in the ring of fire, sits between the Eurasian plate (EP) and the Philippine Sea plate (PSP) is prone to earthquakes experiencing strong ground motions. On February 6, 2016 at 3:57 am local time, a magnitude- 6.4 in- land and shallow earth-quake hit southern part of Taiwan and the casualties of 117 died and 546 wounded. More than 60 buildings totally or partially collapsed. The epicenter is located at Meinong, Kaohsiung City with a focal depth of 16.6 Kilometers. According to the shake records, the strongest intensity reached scale 6 (334.1 gal) (Fig 6).

For better emergency preparedness, response and recovery; we conduct the seismic risk and situation assessment to further support the CEO) operation while earth-quakes. NCDR, as the think tank, provided the integrated multidisciplinary scien-tific suggestions on scenario-based GIS mapping for decision-making. The Earth-quakes Impact 
Analysis Models were developed for urban areas to tackle the large-scale earthquakes and further identify weak points of critical infrastructure, i.e., buildings, roads, and lifelines. (Fig. 7)

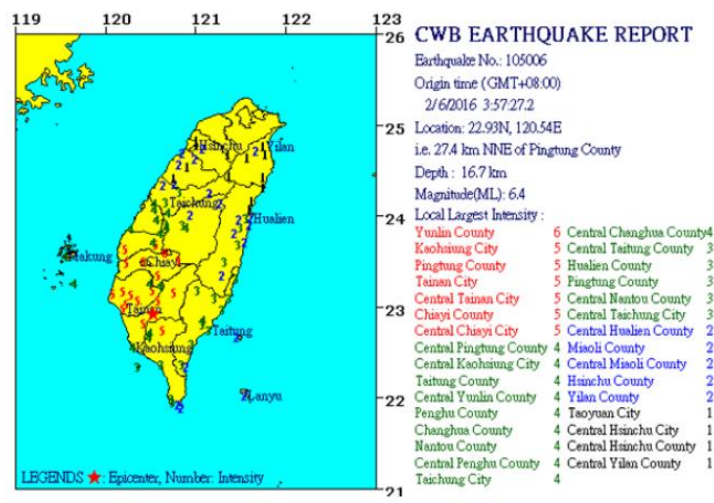

Earthquake Report

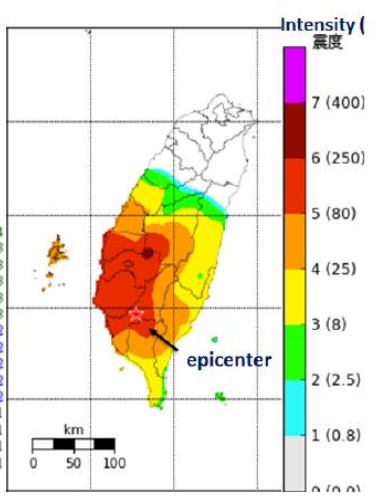

Shake Map

Fig. 6. A Strong Ground Motion in 2016 (12)

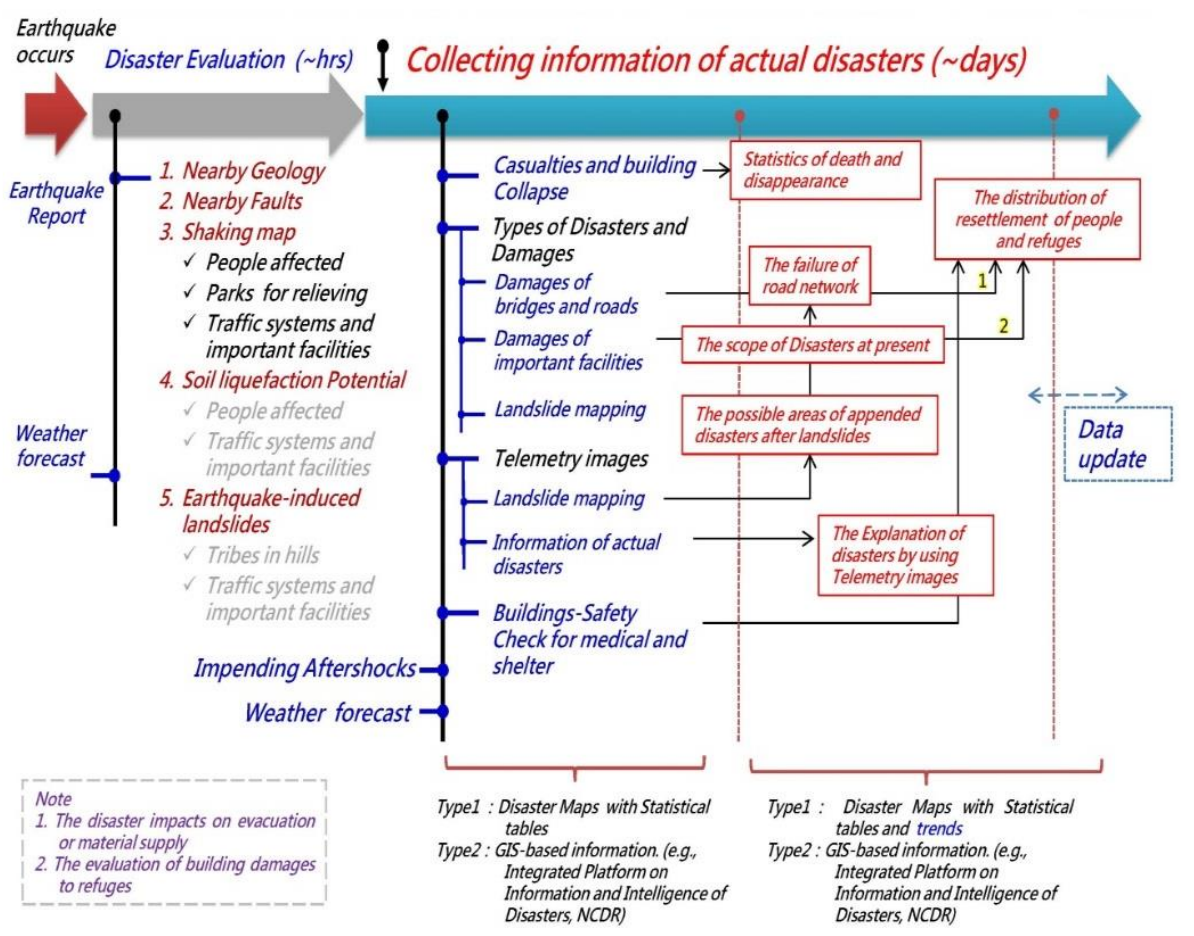

Fig. 7. Data process framework in the case of earthquake in Taiwan CEOC operation (13) 


\section{Emergency Operations}

Right after the strong quake, the Ministry of the Interior activated quick damage survey at and elevated level of emergency operation to level 1 at 4:15 am on Feb 6 to collect situations, and coordinate search and rescue efforts. The operation of search and rescue ended at 4:00 pm on Feb 14. In total, 29,000 of urban search- and- rescue team, firefighters, police officers, volunteers and soldiers had ever joined the operation.

Economy of Taiwan is an indispensable partner in the Global Value Chains of Electronics Industry (14) Most of the manufacturing lines of high tech industries are vulnerable to vibration. Regions most at risk when Kaohsiung Earthquake shook an electronics hub in Southern Taiwan (Fig. 8), where lies at the heart of Apple's supply chain (15) a couple of days before Chinese New Year, a big day for family re-union. The water, electricity, transportation and communications services inter-rupted within 2 to 7 days. Major highways, highway bridges, railway. Taiwan High Speed Rail (THSR) system suspended south- bound service from Taichung for 2 days.

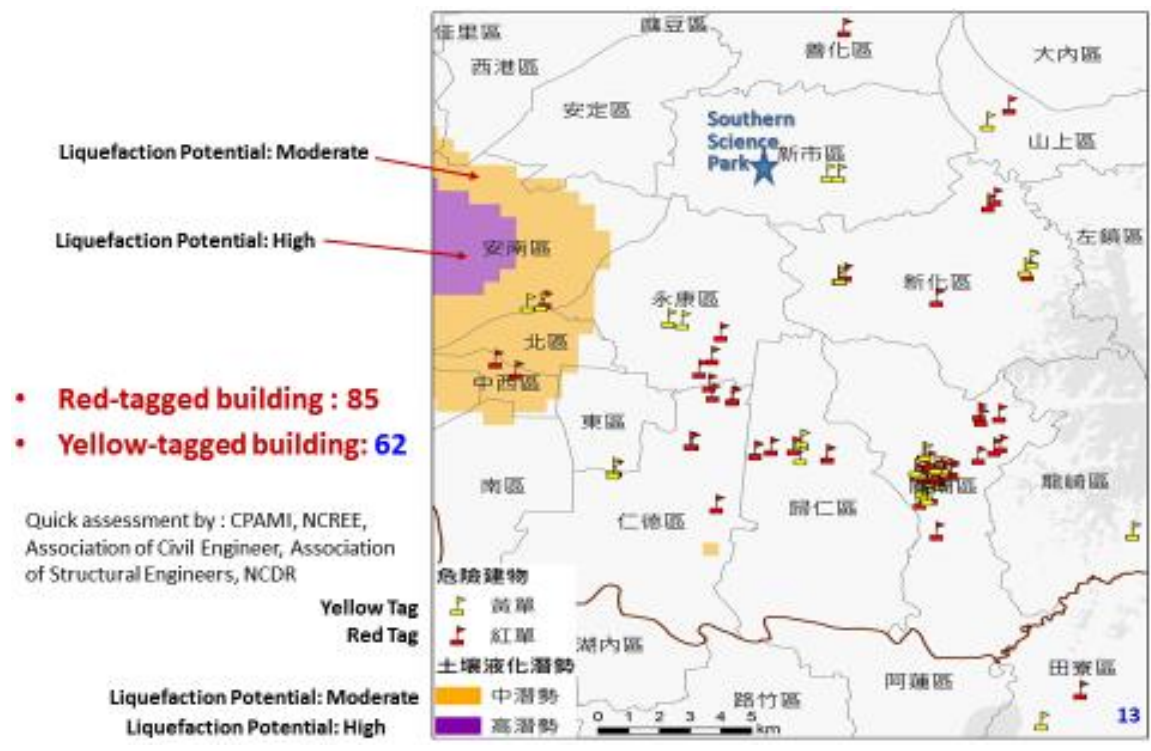

Fig. 8. Locations of Southern Science Park and damaged buildings and liquefaction zone

TSMC, APPLE's sole supplier and Qualcomm's supplier, operates its largest 12inch wafer production facilities in the Southern Taiwan Science Park. As a leading com-pany, TSMC incorporate BCP in its risk management with its suppliers. In the case of Kaohsiung Earthquake, TSMC minimized the losses at 'work in progress' no more than 1 percent of its first-quarter shipments (16). It is inevitable to have loss with the automatic safety measures at a plant in Tainan triggered equipment shut-down but soon resume to operate. Fortunately, TSMC's maintain more than 95 per-cent of the tools fully function after restored in two to three days. Staff were safe and the firm's Tainan facilities were structurally intact. 
In the past two decades, TSMC invested resources on BCP/BCM to strengthen the capability of its suppliers and endeavored to minimize the supply chain interrup-tion in time of disasters. Nowadays, emerging technologies speed up the telecom-munications development and shorten the lead time from data to deliverable mes-sages in the digital age. Hence, the Taiwan government operated the emergency response to help business in responding to the disaster and provide big data and open data assessment and take preemptive measure enhance disaster resiliency in the science park.

TSMC also learn to improve and restructure disaster management framework for emergency operation both after the Typhoon Morakot in 2009 which brought rec-ordbreaking rainfalls with massive floods and large-scale landslides in the south-ern Taiwan and the Great Japan Earthquakes and Tsunami in 2011(17).

\section{APEC Enhances Disaster-Resilient Trade and Investment}

APEC active involvement with voluntary effort contribute to host the train the trainer workshop in the region and explore the future strategies to develop regional BCM approaches after the Great North Eastern Japan Earthquake and Tsunami. Promoting systematic project for capacity building to facilitate the regional collabo-rative efforts on improving business resilience since 2011, APEC BCP related deliv-erables as following:

- Improving Natural Disaster Resilience of APEC SMEs to Facilitate Trade and Investment

- Developing Governments' Capacity to Promote and Facilitate the Effective Use of Business Continuity Planning for Disaster Resiliency (EPWG, Australia)

- APEC Seminar on Capacity Building for Disaster Recovery and Rehabilitation (EPWG)

- Policy Dialogue on Emergency Response Travel Facilitation (ERTF) (EPWG, BMG, SCCP)

- Business Continuity Planning: Policies, Practices and Programs (EPWG, Australia)

- Peer Group Review of BCP booklet/project effectiveness (EPWG, Australia)

- Workshop on Global Supply Chain Resilience (TPTWG, EPWG)

- Seminar on Enhancing Regional Supply Chain Resilience to Disasters in APEC (EPWG)

- Improving the Resilience of the Global Supply Chain (TPTWG, EPWG)

- High Level Policy Dialogue on Resilient SMEs for Better Global Supply Chains (SMEWG, EPWG)

- Sharing outcomes of BCP/PPP at The 6th Asia Ministerial Conference on Disaster Risk Reduction (UNISDR)

- Secure Infrastructure Workshop on Critical Infrastructure Security and Resilience (CTWG, EPWG)

Concerning the complexity to the regional business and emergency preparedness demands, APEC puts the efforts on improving business resilience since 2011, after the Great Japan Earthquakes and Tsunami. APEC aimed at pursuing regional quality and 
sustainable growth on the concept of building the public and private partner-ship capacity to promote and facilitate the effective of business continuity planning for disaster resiliency and deliver number of train-the-trainer workshops. Take into account of critical infrastructure security and resilience, APEC continued to pro-mote the BCP and $\mathrm{BCM}$ in a broader landscape from policy making to capacity build at regional level to enhance disaster-resilient trade \& investment. For SMEs easy implementation, ten easy steps and guidelines of business continuity planning on strengthening supply chains. Forty one SME disaster resilient policies/programs from 12 APEC economies have been collected and organized to help economies design their own disaster resilience policies (18).

$\mathrm{BCP}$ project has been recognized as the top 10 APEC milestones to chart 25 Years of APEC Progress in 2014. Since 2011, APEC Leaders emphasis on fostering business continuity, the application of science and technology in disaster preparedness and risk reduction to build sustainable and resilient communities and to secure global supply chains and facilitate trade and investment. The outputs and its impacts successfully draw the global attention and recognized by UNISDR. APEC continue to promote, share the achievement and supported BCP/PPP implementation in APEC region.

\subsection{The Concept of Regional Collaborations}

$\mathrm{BCP} / \mathrm{BCM}$ capable is the key to maintain the country's comparative advantage (19), the corporate competitive advantage (20) and stabilize the industries while disasters, we have to safeguarding the transboundary economic activities with end-to-end concept for join operation at regional level for GVC/supply chain resiliency (Fig end to end). With sustainable buyers and suppliers, the quality growth of regional economic activities can be sustained if supply chain interrupted by natural disasters.

Engaging regional collaboration on capacity building for disaster risk reduction (DRR), emergency response, preparedness and recovery is the global trend. With the synergy of the PPP, the whole society can work more closely together and share the best practices on DRR for better management/business process and emergency preparedness. For DRR synergy on supply chain resiliency, the join efforts to develop international, regional, subregional and transboundary cooperation through innovative technology/tools is a must. The emergent BCP/BCM can help to enhance the GVCs/supply chain resilience if interruption in terms of quick recovery. To fulfill the goals, the global community shall work together to build networking on the regional BCP/BCM with PPP collaborations on DRR.

A disaster resilient supply chain network can coach its strategic process for operations to adapt to risk that affects its capacities. The upstream and downstream activities can be sustainable through collaboration across the network coping with the dynamic market place in terms of demand and supply with flexibility. Incorporating regional $\mathrm{BCP} / \mathrm{BCM}$ into business operations leads to an emergent competitiveness for sustainability in the global market. It is critical if enhancing the risk awareness of SMEs to uphold the economic growth in APEC region. We can benefit from sharing the natural disaster risks and the best practices while formulating BCP/BCM. 
The increasing frequency and intensity of large scale disasters such as typhoon, extreme weather and volcano eruption can disrupt public services on transportation flights, rail service for shipping where production networks depend on. To take reference on NHK Special - disasters on big data (21) that illustrate the key to overlapping of hazard map and business operation on exposure to hot spot, identifying the problem of social development and the complexity of doing business in product delivery. It becomes supply chain's major challenges for DRR in supply chain resilience. Using innovative Internet of Thing (IoT) tools, big data and open data for business vulnerability assessment at regional level is convenient and widely accept by APEC economies to mitigate the supply chain interruption.

Continuing the effort in promoting supply chain resilience, it is critical to build a GIS-based information intelligence platform for information sharing. Through technology support and collaborations, the interoperability can be feasible to pro-mote scenario-based exercises. From the historical events, we share the experience to improve in the future. The implement of $\mathrm{BCP} / \mathrm{BCM}$ at regional level can enhance regional disaster resilient trade and investment through:

\subsection{End-To-End Scenario-based information sharing and join exercises:}

It is critical to incorporate the major large-scale disasters and historical data in the region for exercises. For example, the Great East Japan Earthquake or the floods in Thailand (22) which hamper the cross-border supply chain resilience. APEC EPCC will continue the effort to promote $\mathrm{BCP} / \mathrm{BCM}$ and build up an operational frame-work at regional level to build the information intelligence platform for DRR and emergency preparedness. It will be the hub of the APEC region to share the common picture for emergency preparedness via regional digital preparedness (23) initiatives.

\subsection{Concept of Regional Operational Framework for Emergency Preparedness}

For encouraging wider, more effective business continuity planning in APEC economies to mitigate risks, APEC Emergency Preparedness Capacity Building Center (EPCC) (24) and NiTech co-hosted 'the 2017 APEC Summit on Resilience and Capacity Building Training Workshop on Promoting Business Connectivity in Nagoya' (25) to explore the challenges with actions on BCM. Connecting the 'Business Clusters' cross-border toward supply chain resiliency, we conclude the preliminary approaches for regional BCM are to collaborate on : 1) information and risk sharing; 2) BCM-based operation; 3) possible damage assessment to critical infrastructure protection (CIP) impact on business operation for recovery; 4) join operations net-working; 5) common operating picture for join operation.

To sum up, a user friendly GIS-based cross-border evidence-based emergency operation for join operation is key to secede the end-to end scenario-based exercise and shoulder the knowledge-based experience transfer for the regional BCM. The crossborder join operation required newly innovative IoT tools, ICTs, big-data and open data for cross-border situation assessment with join efforts to facilitate business resumption. 
With common operation picture on real-time monitoring data integration, the GISWeb-based platform can synergized support though the join discussion for cross-border collaboration on public private partnership.

\section{Conclusion to Move Forward - Enhancing Cross-Border Collaboration in Promoting Regional BCP/BCM}

The ever-changing environment triggered the frequency and intensity of natural disasters which scaling up the risks level and impact of the economic activities. APEC pursue the GVCs and supply resilience to host the APEC Summit on Resilience and Capacity Building Training (26) in Japan to invite the stakeholders' participation to brain storming the future perspectives on developing regional $\mathrm{BCP} / \mathrm{BCM}$ in two dimensions including:

\subsection{Synergize work on regional $\mathrm{BCP} / \mathrm{BCM}$ - cross sectorial collaborations}

- Managing risks and impacts of natural disasters to business in the AsiaPacific region with Public-Private Partnership

- To offer feasible solution package to enhance regional resilience

- To initiate a pilot study on BCM-based supply chain

- Seeking leadership and coordination for cross-sectorial coordination

- To engage key stakeholders though Public Private Partnership

- To keep flexibility among Private Sector, NGOs, NPOs and government to take leading role

- To manage risk of critical infrastructures

\subsection{Accumulation of knowledge, experience and know-how of BCP and BCM}

- Information-intelligence knowledge Platform

- To build up Integrated systems and database adopt Open Data Approach

- To design scenario-based joint drill in the APEC region

- To involve the disaster risk management with financing sectors

- To keep BCM rating transparent

- To discuss Disaster sign standard for risk communication

- knowledge transfer and the best Practices sharing of BCM

- To share information

- To share experiences of formulating BCPs

- To provide solution package on challenges while implementing BCPs

To work as a team, ensure no business know-how will be disclosed for disaster management, adopt innovative user friendly technology for collaboration, provide common 
picture on situation and clearly define the role, level of response and involvement for both public and private sectors are key to success. As a whole, the regional strategies through technology and collaboration for large-scale disasters must be:1) smart and convenient using common picture of situation for operation instead of language communication; 2) on scenario-based; 3) cost effective for response and preparedness

\section{References}

1. APEC SME Crisis Management Center website, https://www.apec-epwg.org/, Multi-Year Project: Improving Natural Disaster Resilience of APEC SMEs to Facilitate Trade and Investment, complete report and guidebook, last accessed 2018/03/30

2. Sendai Framework for Disaster Risk Reduction 2015 - 2030

3. 2017 Global platform for disaster risk reduction: Proceedings; https://www.unisdr.org/we/inform/publications/55465, last accessed 2018/03/30

4. APEC Website, www.apec.org, last accessed 2018/03/30

5. Minister of Science and Technology (MOST), Taiwan website, last accessed 2018/03/30

6. APEC Website, https://www.apec.org/-/media/Files/AboutUs/Infographics/20140519_infograph_sme_hires.jpg, www.apec.org, last accessed 2018/03/30

7. Taiwan Statistic Data Book 2017

8. Minister of Science and Technology and Minister of Foreign Affairs, Taiwan, https://taiwantoday.tw/news.php?unit=2,6,10,15,18\&post=112944, last accessed 2018/03/30

9. TSMC website, http://www.tsmc.com/download/csr/0820tsmc-csr-e/19-24.pdf, last accessed 2018/03/30

10. Henry Mintzberg, The Strategy Process: Concepts, Contexts, Cases, Pearson Education, 2003

11. . Porter, M. E.: How Competitive Forces Shape Strategy. 59 (2), 137-145 (May.1979)

12. APEC Website, https://www.apec-epwg.org/public/uploadfile/act/60707dc7b3eec3a521aa4be922324384.pdf, last accessed 2018/03/30

13. National Science and Technology Center for Disaster Reduction website

14. World Bank website, https://unstats.un.org/unsd/trade/s_geneva2011/refdocs/RDs/GVC\%20in\%20Electronics\%20Industry\%20(Sturgeon\%20\%20Sep\%202010).pdf, last accessed 2018/03/30

15. Forbes / Business/ Feb 29, 2016, The Taiwanese Earthquake That Nearly Flattened The Apple iPhone 7, https://www.forbes.com/sites/jwebb/2016/02/29/the-taiwanese-earthquakethat-nearly-cancelled-the-apple-iphone-7/\#1 eccd0724da7, last accessed 2018/03/30

16. Taipei Times, Silicon wafers damaged in earthquake, TSMC says, Sun, Feb 07, 2016 - Page 3 , last accessed 2018/03/30

17. APEC website, http://mddb.apec.org/documents/2011/EPWG/WKSP1/ 11_epwg_wksp1_012.pdf, last accessed 2018/03/30

18. APEC SME Crisis Management Center, Multiple-year Project on Disaster Resilience Building for SMEs in APEC, 2011. (M SCE 02/2011A_Improving Natural Disaster Resilience of APEC SMEs to Facilitate Trade and Investment) http://www.apec-epwg.org/public/uploadfile/act/2c0ca0199ba34676c3a21032d8e03918.pdf

19. Keuschnigg, M.: Comparative Advantage in International Trade: Theory and Evidence, (2012).

20. Porter, M. E.: Competitive Advantage: Creating and Sustaining Superior Performance, 2008

21. NHK website, http://www.nhk.or.jp/datajournalism/about/index_en.html, last accessed 2018/03/30 
22. Thai flooding impact spreads across world for Toyota, October 27, $2011 \mathrm{https}$ ://www.reuters.com/article/us-toyota/thai-flooding-impact-spreads-across-world-for-toyotaidUSTRE79Q43I20111027, last accessed 2018/03/30

23. Yanling Lee, Kenji Watanabe, Wei-Sen Li, Enhancing Regional Digital Preparedness on Natural Hazards to Safeguard Business Resilience in the Asia-Pacific, Springer International Publishing, (2017).

24. Emergency Preparedness Capacity Building Center https://www.apec-epcc.org/

25. APEC website, APEC Summit on Resilience and Capacity Building Training Workshop on Promoting Business Connectivity, 2017

26. Emergency Preparedness Capacity Building Center website, https://www.apec-epcc.org, last access 2018/03/30 